\title{
Formulation and Evaluation of Fast Dissolving Buccal Film of Curcumin as Promising Route of Buccal Delivery
}

\author{
Snehal S. Patil *, Shivani J. Patil, Rohan R. Vakhariya, Dr. A.R. Chopade, Dr. S. K. Mohite \\ Rajarambapu College of Pharmacy, Kasegaon, Tal. Walwa, Dist. Sangli, Maharashtra, India. \\ Email Id: patilsnehal5121@gmail.com
}

D.O.I - 10.51201/JUSST/21/05/157

https://doi.org/10.51201/JUSST/21/05157

\begin{abstract}
:
The present work is mainly focused on preparing fast dissolving buccal films of Curcumin solid dispersion, since Curcumin is a poorly soluble drug. The main aim of this is to provide quick onset of action, improved bioavailability and also to increase the patient convenience of administration. The rate of dissolution can be increased by incorporating the solid dispersed drug into film which is prepared by HPMC-K100 as polymers, glycerin as a plasticizer, sorbitol as an antioxidant, Tween \& Span as a non-ionic surfactant. The films were evaluated for their physiochemical parameters like disintegration time, surface $\mathrm{pH}$, thickness, weight, percent moisture absorption, folding endurance, drug content and stability testing. The invention is to produce mucoadhesive buccal patches, which heals the lesion/ injury with replacing patches.
\end{abstract}

Keywords: Curcumin, Solid dispersion, Bioavailability, Rate of dissolution, Mucoadhesive. 


\section{INTRODUCTION:}

There is always increasing demand for patient convenience. Among the various routes, the oral route is most popular route for the administration of therapeutic agents because of the low cost of therapy and ease of administration which leads to high levels of patient compliance. ${ }^{1}$ Generally geriatric, pediatric and bedridden patient as well as travelling patients who may not have ready access to water experience difficulties in swallowing the conventional oral dosage form. Many pediatric and geriatric patients are unwilling to take solid preparations due to fear of choking. Even with fast dissolving tablets there is a fear of choking due to its tablet type appearance. To overcome this problem a novel formulation i.e. oral fast dissolving films which is very thin oral strip, which is simply placed on the patient's tongue or any oral mucosal tissue (buccal /sublingual), instantly wet by saliva, and then film rapidly hydrates and adheres onto the site of application. It then rapidly disintegrates and dissolves to release the medication in mucosal cavity. ${ }^{2}$ This fast dissolving action is primarily due to the large surface area of the film, which wets quickly when exposed to the moist oral environment. Buccal films offer an attractive route for systemic drug delivery. Solubility is based on the high-dosage capacity of the immediate release product. ${ }^{3}$ The improved systemic bioavailability results from bypassing first pass effect and better permeability due to a well-supplied vascular and lymphatic drainage. Fast dissolving films recently have acquired great importance in the pharmaceutical industry due to their unique properties and specific advantages like no need of water for disintegration, accurate dosing, rapid onset of action, ease of transportability, ease of handling, good mouth feel and improved patient compliance. ${ }^{4}$ These films have potential to deliver the drug systemically through intragastric, sublingual or buccal route of administration and also have been used for local action. ${ }^{5}$

A huge investigation exposed that turmeric and curcumin has an extensive variety of curative property such as anti-inflammatory, antibacterial, antifungal, anticancer, antispasmodic, antioxidant, anti-amoebic, anti HIV, anti-diabetic, anti-fertility etc. ${ }^{6}$ Curcumin, a golden color attained by Curcuma longa is been used from the time immemorial as a nutritional complement, coloring means, spice and also for therapeutic the purpose. It is also accounted that the curcumin safe and sound up to $8 \mathrm{~g} / \mathrm{day}$. ${ }^{7}$ Curcuminioids, the oleoresins, resultant by ethanolic extraction of turmeric are mainly liable for golden colour and are believed liable for the natural actions. In neutral and acidic situation curcumin shows keto form. In acidic condition curcumin performs as an influential hydrogen patron. ${ }^{8}$ For improving solubility, dissolution behaviour and on set of action solid dispersion is one of the preferable techniques. It rivet a spreading of one or more drug component in an inert transporter or matrix in solid state set by melting, dissolution in solvent or melting solvent method. The method has been used for a broad range of weakly water soluble active ingredients such as Nimesulide, Tenoxicam, Nifedipine, Nimodipine etc.

The present work was aimed to improve the bioavailability and efficacy of Curcumin by preparing rapidly dissolving buccal films. Among varies techniques Solid dispersion have been used to increase the solubility and dissolution rate of poorly water soluble drugs, it is the most frequently and effectively used one. The methods used to prepare solid dispersion include fusion (melting) method, solvent evaporation method and solvent wetting method. Different watersoluble carriers have been employed for preparation of solid dispersion; the most common ones are various grades of polyethylene glycols (PEG), polyvinyl pyrrolidone (PVP), $\beta$ - cyclodextrin, lactose, and Hydroxyl propyl methylcellulose (HPMC) ${ }^{9}$. 


\section{Advantages of Buccal Film:}

1. It is richly vascularised and additional reachable for administration and removal of formulations.

2. Patient accessibility is high.

3. Retentive dosage forms are suitable for administration.

4. Improves bioavailability by eliminating first pass metabolism.

5. Surface of buccal mucosa achieves a fast cellular recovery.

6. Low enzyme activity.

7. Non-invasive method of drug administration.

8. Ability to incorporate permeation enhancer in the formulation.

\section{Disadvantages of Buccal Film:}

1. Buccal membrane has low permeability.

2. Small surface area $\left(170 \mathrm{~cm}^{2}\right)$.

3. Continuous secretion of saliva results in following dilution of the drug.

4. Inconvenience route of drug administration when the patient is swallowing or taking.

\section{Classification of Buccal Bioadhesive Dosage Forms:}
A. Buccal Bioadhesive Tablets.
B. Buccal Bioadhesive Semisolids
C. Buccal Bioadhesive Patch and Films
D. Buccal Bioadhesive Powders

\section{A. Buccal Bioadhesive Tablets:}

Buccal bioadhesive tablets are dry dosage forms that are to be moistened prior to placing in contact with buccal mucosa. Double and multilayered tablets are already formulated using bioadhesive polymers and excipients. The two buccal bioadhesive tablets commercially available buccal bioadhesive tablets in UK are "Bucastem" and" Suscard buccal'.

\section{B. Buccal Bioadhesive Semisolid Dosage Forms:}

Buccal bioadhesive semisolid dosage forms consists of finally powdered natural or synthetic polymer dispersed in a polyethylene or in aqueous solution, Example: Arabase. 21

\section{Buccal Bioadhesive Patches and Films:}

Buccal bioadhesive patches consists of two ply laminates or multilayered thin film round or oval as consisting of basically of bioadhesive polymeric layer and impermeable backing layer to provide unidirectional flow of drug across buccal mucosa. Buccal bioadhesive films arc formulated by incorporating the drug in alcohol solution of bioadhesive polymer. 


\section{Buccal Bioadhesive Powder Dosage Forms:}

Buccal bioadhesive powder dosage forms are a mixture of Bioadhesive polymers and the drug and are sprayed onto the buccal mucosa the reduction in diastolic B.P after the administration of buccal tablet and buccal film of Nifedipine.

\section{MATERIALS AND METHODS:}

\section{Materials:}

Curcumin was obtained from the local market. Chemicals such as glycerin, sorbitol, tween \& span used were of analytical grade. HPMC used as polymer was obtained from college store.

\section{Methods:}

\section{Preformulation Studies:}

Preformulation studies characterize the physical, chemical and mechanical properties of new drug substances, in order to develop stable, safe and effective dosage forms.

\section{Method of Preparation of Buccal Film:}

a. Glycerin, Sorbitol, Tween \& Span were mixed and was slightly heated till $60^{\circ} \mathrm{C}$.

b. Then the solution was stirred at $500 \mathrm{rpm}$ by using magnetic stirrer for 30 minutes.

c. HPMC K-100 was added to the above prepared solution and the solution was cooled to room temperature.

d. Stirred above solution at $500 \mathrm{rpm}$ for 20 minutes.

e. After that add curcumin and allow the solvent to evaporate.

f. The solution so formed was poured in the petridish and the petridish was dried in hot air oven for $30 \mathrm{~min}$ at $110^{\circ} \mathrm{C}$.

g. The thin film was formed and then it was cut in the square size shapes.

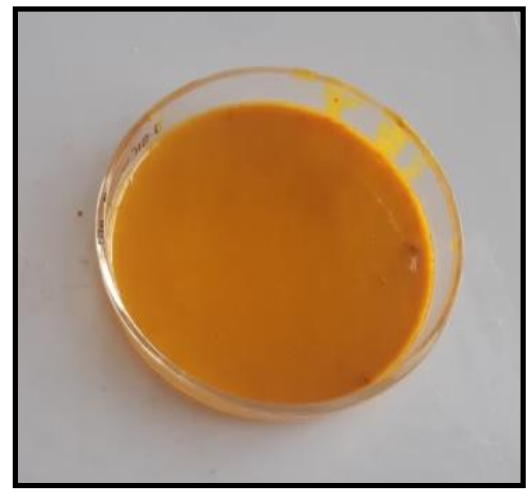

Fig. No. 1: The Wet Film in Petri dish

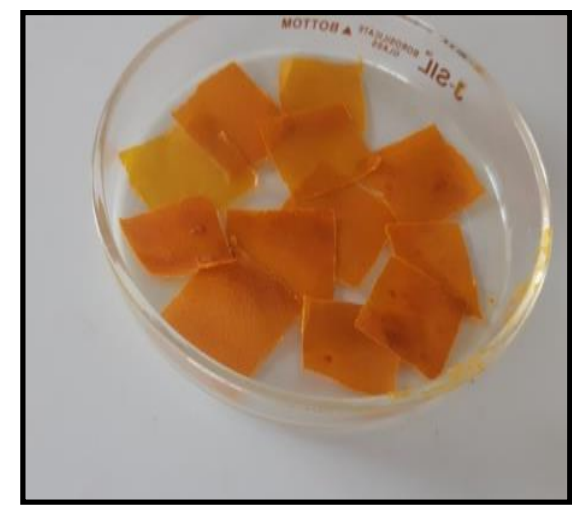

Fig. No. 2: Square Shape Cut Buccal Films 
Formulation Table:

\begin{tabular}{|c|c|c|c|c|c|c|}
\hline Ingredients & F1 & F2 & F3 & F4 & F5 & F6 \\
\hline Curcumin & $1.2 \mathrm{gm}$ & $1.2 \mathrm{gm}$ & $1.2 \mathrm{gm}$ & $1.2 \mathrm{gm}$ & $1.2 \mathrm{gm}$ & $1.2 \mathrm{gm}$ \\
\hline HPMC K100 & $2.5 \mathrm{gm}$ & $3.0 \mathrm{gm}$ & $3.5 \mathrm{gm}$ & $2.5 \mathrm{gm}$ & $2.5 \mathrm{gm}$ & $2.5 \mathrm{gm}$ \\
\hline Glycerin & $1.0 \mathrm{gm}$ & $1.0 \mathrm{gm}$ & $1.0 \mathrm{gm}$ & $4.5 \mathrm{gm}$ & $5.0 \mathrm{gm}$ & $7.0 \mathrm{gm}$ \\
\hline Sorbitol & $0.5 \mathrm{gm}$ & $0.5 \mathrm{gm}$ & $0.5 \mathrm{gm}$ & $0.5 \mathrm{gm}$ & $0.5 \mathrm{gm}$ & $0.5 \mathrm{gm}$ \\
\hline Tween \& Span & $0.25 \mathrm{gm}$ & $0.25 \mathrm{gm}$ & $0.25 \mathrm{gm}$ & $0.25 \mathrm{gm}$ & $0.25 \mathrm{gm}$ & $0.25 \mathrm{gm}$ \\
\hline Distilled Water & q. s. & q. s. & q. s. & q. s. & q. s. & q. s. \\
\hline
\end{tabular}

Table No. 1: Formulation table to prepare buccal film of Curcumin

\section{Evaluation Test for Buccal Film:}

\section{Visual inspection:}

Properties such as homogeneity, colour, transparency and surface of the oral films were evaluated for all the prepared films. ${ }^{8}$

\section{Weight variation:}

The weight variation of the buccal film was done by weighing twenty films individually and the average weight was calculated. For the film to be accepted, the weight of not more than two films deviates from the average weight by not more than $7.5 \%$ and no film deviates by not more than $15 \%$.

\section{Folding endurance test:}

It gives an indication about brittleness of the film. The folding endurance of randomly selected films was determined by repeatedly folding one film at the same place till it break or folded maximum 250 times and the values were reported.

\section{Disintegration time:}

The disintegration time was measured using modified disintegration method. For this purpose a petridish was filled with $10 \mathrm{ml}$ of water. The film was carefully put in the centre of petridish. The time for the film to completely disintegrate in to fine particles was noted.

\section{Drug content:}

Drug content of all films was determined by UV Spectrophotometric method. For this $2 \times 3 \mathrm{~cm}^{2}$ strip was dissolved in $100 \mathrm{ml}$ of phosphate buffer of $\mathrm{pH} 6.8$ and solution was stirred for $1 \mathrm{hr}$ on a magnetic stirrer. The solution was filtered and absorbance was recorded at $421 \mathrm{~nm}$. Drug content was calculated by using standard curve of drug. ${ }^{9}$ 


\section{Thickness measurements:}

The thickness of each film was measured at five different locations (centre and four corners) using micrometer screw gauge. This is essential to ascertain uniformity in the thickness of the film as this is directly related to the accuracy dose in the strip. ${ }^{10}$

\section{Surface pH study:}

The surface $\mathrm{pH}$ of the buccal patches was determined in order to investigate the possibility of any side effects in-vivo. As an acidic or alkaline $\mathrm{pH}$ may cause irritation to the buccal mucosa, it was determined to keep the surface $\mathrm{pH}$ as close to neutral as possible. A combined glass electrode was used for this purpose. The buccal patch was allowed to swell by keeping it in contact with $1 \mathrm{ml}$ of distilled water for $1 \mathrm{~h}$ at room temperature. The $\mathrm{pH}$ was measured by bringing the electrode in contact with the surface of the patch and allowing it to equilibrate for 1 min. The experiment was performed in triplicate, and average values were reported.

\section{RESULTS AND DISCUSSION:}

\section{Evaluation Test for Buccal Film:}

All the prepared fast dissolving buccal films were evaluated for their physiochemical parameters like disintegration time, surface $\mathrm{pH}$, thickness \& weight of the films, folding endurance, drug content and the values are shown in Table 2.

\section{Visual inspection:}

All the films prepared were found to be flexible, smooth, non-sticky, homogenous, yellow colored and transparent with no visible particulate matter.

\section{Weight variation:}

The observed results of Weight variation test are shown in Table 2. The results reveal that the weight of the films varied with polymer concentration. Increase in polymer concentration resulted in increase in weight of the film, but the increase was marginal.

\section{Folding endurance:}

Folding endurance gives an indication of about brittleness of the film. The folding endurance values of the prepared films ranged from 42.3 to 78.3 percent. The optimized F6 film was found to have folding endurance of $78.3 \%$. The results showed that as the concentration of plasticizer increases, folding endurance of fast dissolving film increases.

\section{Disintegration time:}

It was observed that in-vitro disintegration time varies from 44-92 sec for all the formulations. In-vitro disintegration time of the films was found to be increased with increasing the concentration of the polymer, because high concentration of polymer resulted in a thicker gel upon contact with the medium, resulting in longer disintegration time. It was also found that the disintegration time increased none significantly on increasing the concentration of glycerin (plasticizer).

\section{Drug content:}

Drug content in the films was evaluated and the values were found to be between 94.51 to $98.22 \%$. All the films were found to contain an almost uniform quantity of the drug, as per content uniformity studies indicating reproducibility of the technique. As per the USP 
requirements, the films found to meet the criteria for content uniformity (85-115) \% of the label claim. No significant difference in the drug content among the films indicated that the drug was dispersed uniformly throughout the $6 \mathrm{~cm}^{2}$ constant area of the film.

\section{Thickness measurements:}

Thickness of fast dissolving film depends on the concentration of polymer. Thickness of all mouth dissolving film was measured with micrometer screw gauge. The thickness was found to vary between 0.3 to $0.8 \mathrm{~mm}$ with very low standard deviation value (Table 2). A very low standard deviation value is indicating that the method used for the formulation of films gives films of uniform thickness and hence dosage accuracy in each film can be ensured. The results of thickness measurement indicating that as the concentration of polymer increases, thickness of fast dissolving film increases.

\section{Surface pH study:}

The surface $\mathrm{pH}$ of all the films was found between 6.3 to 6.84 . The surface $\mathrm{pH}$ of all the formulations were close to the neutral $\mathrm{pH}$, which indicated that films may have less potential to irritate the buccal mucosa, and hence more acceptable by the patients.

\begin{tabular}{|c|c|c|c|c|c|c|}
\hline Batch & $\begin{array}{l}\text { Weight } \\
\text { (mg) }\end{array}$ & $\begin{array}{c}\text { Folding } \\
\text { Endurance } \\
(\%)\end{array}$ & $\begin{array}{c}\text { Disintegration } \\
\text { Time (sec) }\end{array}$ & $\begin{array}{c}\text { Drug } \\
\text { Content }\end{array}$ & $\begin{array}{c}\text { Thickness } \\
\text { (mm) }\end{array}$ & $\begin{array}{c}\text { Surface } \\
\text { pH }\end{array}$ \\
\hline F1 & $55.6 \pm 1.24$ & $55 \pm 0.40$ & $57.0 \pm 0.01$ & $94.7 \pm 0.45$ & $0.46 \pm 0.01$ & $6.3 \pm 0.07$ \\
\hline F2 & $59.3 \pm 0.33$ & $51 \pm 0.68$ & $71.0 \pm 0.04$ & $97.17 \pm 0.80$ & $0.5 \pm 0.01$ & $6.84 \pm 0.10$ \\
\hline F3 & $65.6 \pm 0.24$ & $42.3 \pm 0.61$ & $92.4 \pm 0.33$ & $98.22 \pm 0.19$ & $0.8 \pm 0.01$ & $6.56 \pm 0.04$ \\
\hline F4 & $52.3 \pm 0.23$ & $51.3 \pm 0.3$ & $44.0 \pm 0.01$ & $94.51 \pm 0.70$ & $0.62 \pm 0.02$ & $6.6 \pm 0.04$ \\
\hline F5 & $59.3 \pm 0.42$ & $64.1 \pm 0.24$ & $46.0 \pm .020$ & $95.21 \pm 0.80$ & $0.32 \pm 0.03$ & $6.73 \pm 0.03$ \\
\hline F6 & $63.6 \pm 0.36$ & $78.3 \pm 0.56$ & $47.0 \pm 0.01$ & $97.61 \pm 0.34$ & $0.30 \pm 0.22$ & $6.68 \pm 0.02$ \\
\hline
\end{tabular}

Table no.2.The physicochemical parameters of buccal films of Curcumin

\section{CONCLUSION:}

The drug released which was desirable for fast absorption. Hence fast dissolving films of Curcumin was the most suitable dosage form for clinical use in the treatment of mouth ulcers, where a quicker onset of action for a dosage form is desirable along with the improved bioavailability and convenience of administration. Thus curcumin films can be easily administered by pediatrics and geriatrics that are under the medication of Curcumin. With this 
formulated unidirectional bilayered buccal bioadhesive film for curcumin using HPMC as mucoadhesive agent is superior to oral conventional tablets or films, as it has the potential to bypass the first pass metabolism and improve the bioavailability of curcumin. It is therefore expected to reduce adverse effect, cost and ultimately improve the patient compliance.

\section{REFERENCES:}

1. Swapnil L. Patil, Paresh R. Mahaparale, Madhavi A. Shivnikar, Shradha S. Tiwari, Ketan V. Pawar, Prashant N. Sane., Fast dissolving oral films: an innovative drug delivery system, International Journal of Research and Reviews in Pharmacy \& Applied Sciences, 2014; 2(3): 482-496.

2. Nishi Thakur, Mayank Bansal, Neha Sharma, Ghanshyam Yadav and Pragati Khare, Overview "A Novel Approach of Fast Dissolving Films and Their Patients", Advan. Biol. Res., 2013; 7(2): 50-58.

3. Priyanka R. Patil*, Mr. Rohan R. Vakhariya, Dr. C. S. Magdum, Solubility as well as Bioavailability Enhancement Techniques, Research Journal of Pharmaceutical Dosage Forms and Technology, 2019, 11(2), 1-6.

4. A Arun; C Amrish, Fast Dissolving Oral Films: An Innovative Drug Delivery System, International Journal of Chem Tech Research, 2010; 2: 576-583.

5. SD Barnhart, MS Sloboda, Drug Delivery Technology, 2007; 7(8): 34-37.

6. Rohan R. Vakhariya*, Rutuja R. Shaha, Archana R. Dhole, Dr. C.S Magdum, Preparation of Novel Biocompatible Honey Hydrogel with Turmaric and Aloe vera, Research Journal of Pharmacology and Pharmacodynamics, 2017, 9(2), 1-4.

7. M.K.Modasiya, V.M.Patel, Studies on solubility of curcumin, International Journal of Pharmacy \& Life Sciences, March 2012; 3(3): 1490-1497.

8. Tejas P, Patel L.D, Adeshara S.P, Timir P, Sunil M, and Tushar P, Dissolution enhancement of fenofibrate by solid dispersion technique, Current Pharma Research, 2011; 1(2): 127-134.

9. Sapkal NP, Kilor VA, Daud AS, Bonde MN., Development of fast dissolving oral thin films of ambroxol hydrochloride: Effect of formulation variables, J. Adv. Pharmaceut. Res., 2011; 2(2): 102-109.

10. G. N. A. Lakshmi, Kumara Swamy $S$ and Agaiah Goud B., Preparation and Characterization of Mouth Dissolving Films of Valsartan Solid Dispersion, JAPS, 2013; 3(1): 415-427. 